\title{
Economic Modelling for Self-Consumption of Roof-Top Photovoltaic Systems in Spain
}

\author{
Álvaro Rodríguez-Martinez ${ }^{1}$ and Carlos Rodríguez-Monroy ${ }^{1, *}$ \\ 1 Department of Industrial Organization, Business Administration and Statistics, E.T.S. Ingenieros \\ Industriales, Universidad Politécnica de Madrid (UPM), calle José Gutiérrez Abascal 2, 28006 Madrid, Spain \\ * Correspondence: carlos.rodriguez@upm.es
}

\begin{abstract}
This article has been developed to assess the economic feasibility of a roof-top photovoltaic installation of industrial self-consumption. Numerical models that enable an interested person to obtain the main expected parameters will be generated. To do this, a calculation methodology will be generated through which the reader, knowing the location of the facility and dimensions of the roof, will be able to calculate the maximum installable power, the main parameters related to production, the cost of the installation, and the LCOE of the plant. The use of actual costs will be facilitated in case they are known, but it will remain possible to apply the costs of the major equipment (modules, inverter, and structure) considered throughout the article. This developed calculation methodology will also allow a quick comparison of the forecasts of production, CAPEX, and LCOE of plants designed with different inclinations and different types of modules. Consequently, it will be especially useful for decision-making before developing the plant's basic engineering. Moreover, the calculations used for modeling the LCOE will be analyzed in depth. This analysis will allow evaluating how the different technical variables affect the profitability of a photovoltaic installation, such as the selected tilt, the location, the module's technology, or the available area.
\end{abstract}

Keywords: sustainability; solar energy; photovoltaic energy; renewable energy; self-consumption; rooftop pv

\section{Introduction}

The decrease in the cost of commercial modules has been progressive since its appearance in the market, exceeding $4 € / \mathrm{Wp}$ in 2001, to become around $1.2 € / \mathrm{Wp}$ in 2012. Nowadays, these prices are between 0.2 and $0.3 € / \mathrm{Wp}$ for self-consumption installations larger than $50 \mathrm{~kW}$, being the scale's economy and the technology selected very important. Technological improvements in modules, inverters, and structures have also appeared. These technical improvements, as well as the significant price depression, make photovoltaic technology to have prospects to sustain continued growth. Currently, the installed power worldwide already is over $700 \mathrm{GWp}$.

This article develops a series of numerical models that allow the reader to evaluate the technical and economic feasibility of creating a photovoltaic installation on a flat roof. For this, numerous facilities of different sizes, technologies, and inclinations have been designed and economically valued, and they have been simulated in four different locations. The results have been used to develop numerical models that easily calculate the production, power, CAPEX, OPEX, Yield, and LCOE, knowing the characteristics of the roof to be analyzed. In the study, current data on the cost and production of photovoltaic systems of 30 different cases will be extracted. Their production and energy cost for four different locations representing most Spanish geography (Centre, North, and South of the Iberian Peninsula, and the Canary Islands) will be studied. This will allow the generation of a database of costs and production that represents the reality of 
photovoltaic installations of industrial self-consumption projected nowadays in the best possible way, using devices equipped with the latest advances in the industry.

Regarding what has been mentioned, a set of photovoltaic systems have been designed meeting the following characteristics:

- Located in Spain.

- Intended for industrial self-consumption.

- With an anti-spilling system.

- In flat roofs with high tolerance to loads.

- $100 \%$ self-consumption.

- Inverters located in the room of the General Low Voltage Board.

- Absence of obstacles.

- Absence of losses by nearby shading.

- Height of the building of $10 \mathrm{~m}$.

The evaluated variables that have been modified for the photovoltaic generation are:

1. Location: facilities have been simulated for the locations of Bilbao (Basque country), Torrejón de Ardoz (Madrid), Seville (Andalusia), and Lanzarote (Canary Islands).

2. Technology: 72-cell modules, using PERC monocrystalline modules and polycrystalline modules.

3. The inclination of the modules: leaps of 5 degrees between $10^{\circ}$ and $30^{\circ}$ inclination.

4. Available area: $1,200 \mathrm{~m}^{2}$ with low voltage connection, $4,000 \mathrm{~m}^{2}$ with low voltage connection and $12,000 \mathrm{~m}^{2}$ with high voltage connection.

Once the type cases are known, the main equipment has been selected, using the manufacturer Huawei inverters and the manufacturer SunTech modules. The software Helioscope has been used to calculate the maximum power available on each of the combinations of the installation that went into the study. Afterward, the basic engineering of the facilities has been done with the proposed design. The different combinations have been valued economically and then simulated at four locations also using Helioscope. The maintenance cost has been valued and finally the LCOE of the 30 facilities has been estimated for the studied locations. Later, the numerical models have been generated. Finally, the calculation methodology has been developed.

As it is mentioned above, a series of numerical models have been generated. The models allow the reader to estimate the maximum power installed and its production, its cost, and its LCOE. It is necessary to perform a series of steps in which the cost of modules, structures, and inverters can be applied for its use. These values could be changed if prices are known (which allows the models to remain valid even though the cost of modules fluctuates, or its performance is improved).

The models permit the rapid calculation of the LCOE with various inclinations and modules' technologies to check what installation approach will present a lower LCOE (and, therefore, a lower payback period). In addition, it allows the reader a quick idea of the installable power, the cost of the installation, its production, and its LCOE without having to carry out the basic engineering of the different facilities or simulate each case separately. However, it is recommended to use these models as a support, and never as a rigid and absolute calculation methodology, as it simplifies the multiple variables that might appear in a photovoltaic system.

\section{Materials and Methods}

The main objective of this project is the generation of numerical models that allow a person interested in the economic valuation of a photovoltaic installation to obtain the main expected parameters. For this, a calculation methodology will be generated through which the reader, knowing the location of the installation and the dimensions of the roof, will be able to obtain: the maximum installable power, the YIELD of said installation, the 
energy production of the first year and the CAPEX, OPEX, and LCOE values of the plant. It will be easier to use real costs if known, but it will be possible to apply the costs of the main equipment (modules, and inverters) considered throughout the project. This developed calculation methodology will also make it possible to quickly compare the production, CAPEX, and LCOE forecasts of projected plants with different inclinations and different types of modules, which will be especially useful for decision-making prior to engineering development.

In addition, the calculations used for modeling the LCOE will be analyzed in depth. This analysis will make it possible to evaluate how the different technical variables that affect the economic viability of a photovoltaic installation influence, such as the selected inclination, the location, the module technology, or the available area. From a financial point of view, the influence of the discount rate and the useful life period of the installation considered will be analyzed. In addition, it will be evaluated how the reduction in costs of the main equipment may have made some commonly accepted design criteria obsolete, such as the conception that the optimal inclination is the one that generates the highest production per module, studying the influence of the economy of scale by reducing the inclination of the modules.

In this process, the cost and production data of the 30 photovoltaic installations designed to generate the models will be extracted. Its production and the cost of energy will be studied for four different locations that represent most of the Spanish geography (Center, North and South of the Peninsula, as well as the Canary Islands), allowing to generate a data base of costs and production that represents in the best possible way the reality of industrial self-consumption photovoltaic installations that are projected today, using equipment that represents the latest advances in the sector.

The variety of possibilities in terms of modules, structures, powers, and configurations makes the number of cases used for the study unlimited. On the other hand, to carry out a comparison that allows drawing conclusions from the results obtained, it is necessary to determine the type of facilities on which the study will focus and consequently to which the models developed will be applicable:

- Facilities located in Spain: to avoid that different weather conditions or the variation in costs from one country to another may distort the comparison.

- Industrial self-consumption facilities: since the decentralization of the electrical system and the low return on investment generated by these facilities make the installation forecasts very high.

- Installations on a flat roof with high tolerance to loads

- Installations with $100 \%$ self-consumption: that is, the study is carried out for installations that take advantage of all the energy they generate because their consumption is much higher at all times than photovoltaic production.

- Inverters located in the room of the General Low Voltage Module.

- Absence of obstacles.

- Absence of losses due to close shading.

- Building height of $10 \mathrm{~m}$.

On these conditions, the calculation methodology will consist of the following steps:

1. Selection of standard cases: the variables that will change from one case to another will be defined to represent as many facilities as possible so that conclusions can be drawn on how they affect the different parameters studied.

2. Selection of main equipment: the modules, inverters, and structures to be used will be chosen. It will represent the latest advances in the sector, using modules improved by PERC type treatments, multi MPPT inverters, and structures without the need to drill the roof.

3. Use of the Helioscope software to calculate the available power: the selected geometries will be generated in Helioscope, and sizing of each of the facilities defined in step 1 will be carried out.

4. Design and basic engineering of the facilities: to subsequently be able to assess the cost of the plants, the wiring, protections, control equipment, and all the necessary 
elements for each of the predefined facilities will be dimensioned, always from the point of view of basic engineering.

5. Calculation of CAPEX: Each facility will be economically valued, budgeting with market prices for materials and assembly. The cost of engineering, business structure costs and any other element that may intervene in the budget of a photovoltaic installation will also be calculated.

6. Simulation of the installations with the Helioscope software: once the photovoltaic plants have been dimensioned, the data entered into Helioscope will be completed. They will be simulated for each of the selected locations, compiling the results obtained.

7. Calculation of OPEX and estimation of LCOE: the cost of maintenance will be economically valued. The calculated values the LCOE for each case can be obtained in the locations studied.

8. Numerical modeling of the LCOE: numerical models will be generated that allow an approximate calculation of the power, production, cost, and LCOE of a photovoltaic installation for a known roof.

2.1 Design and basic engineering of the facilities

Using the Helioscope software, each facility's available power has been calculated, and the appropriate number of inverters has been dimensioned in each case. Next, the basic engineering of the installation has been developed, allowing the sizing of the rest of the equipment that is necessary for estimating the CAPEX of each plant.

\subsection{CAPEX calculation}

As a result of the previous section, all the material costs associated with the 30 photovoltaic installations designed have been calculated, together with the assembly time of each piece of equipment or material.

The results obtained for three of the facilities are shown in Table 1.

Table 1. Cost decomposition grouped by items for the three base cases

\begin{tabular}{|l|c|c|c|}
\hline \multicolumn{1}{|c|}{ Element } & $\mathbf{1 0}$-Mono-1200 & $\mathbf{1 0}$-Mono-4000 & $\mathbf{1 0}$-Mono-12000 \\
\hline Photovoltaic Modules & 41.325 & 143.034 & 413.201 \\
\hline Structures & 7.524 & 27.462 & 77.754 \\
\hline Investors and add-ons & 9.470 & 25.413 & 64.037 \\
\hline DC wiring & 1.811 & 8.900 & 42.351 \\
\hline AC wiring (LV and MV) & 985 & 2.139 & 59.436 \\
\hline Protections and control & 4.686 & 12.480 & 17.470 \\
\hline Mounting & 11.472 & 36.647 & 108.428 \\
\hline Structure of work & 12.916 & 22.176 & 29.918 \\
\hline Miscellaneous expenses & 2.233 & 5.430 & 827.112 \\
\hline Cost & 92.425 & 283.685 & 99.253 \\
\hline Margin & 11.091 & 34.042 & 926.366 \\
\hline Sale & 103.516 & 317.727 & \\
\hline
\end{tabular}

To compare the results obtained, it is necessary to normalize the EPC sales values, converting them to units per installed power $(€ / \mathrm{Wp})$ as shown in Table 2:

Table 2. EPC costs, both absolute and normalized, for the three base cases 


\begin{tabular}{|c|c|c|c|}
\hline Element & $\mathbf{1 0}$-Mono-1200 & $\mathbf{1 0}$-Mono-4000 & $\mathbf{1 0}^{\mathbf{o}-M o n o-12000}$ \\
\hline EPC $(€)$ & 103,516 & 317.727 & 926.366 \\
\hline Power $(\mathrm{kWp})$ & 142.5 & 520.1 & 1559.3 \\
\hline EPC $(€ / \mathrm{Wp})$ & 0.726 & 0.611 & 0.594 \\
\hline
\end{tabular}

\subsection{Simulation of installations with the Helioscope software}

For each facility, both the YIELD and the PR and the production in the four locations have been calculated.

For this, the installations have been simulated using the Helioscope Software. The procedure used has been:

Step 1: The 30 plants have been dimensioned for the location of Madrid with the Helioscope.

Step 2: The meteorological conditions of the simulation have been generated. The numerical models used in the simulation in base case 1 can be seen in the following image. Dirt losses of $2 \%$ have been considered, which correspond to the NREL recommendations for roofs that are cleaned annually [10]. However, $1.5 \%$ is included to compensate for the LID (Light Induced Degradation) losses that appear in the plant in year 1.

The results for the province of Madrid of the three base cases are shown in Table 3.

Table 3. Results of the simulation of the three base cases in the province of Madrid

\begin{tabular}{|c|c|c|c|}
\hline Parameter & $\mathbf{1 0}-$ Mono-1200 & $\mathbf{1 0}$-Mono-4000 & $\mathbf{1 0}$-Mono-12000 \\
\hline PR (\%) & 84.9 & 84.5 & 84.7 \\
\hline Yield $(\mathrm{kWh} / \mathrm{kWp})$ & 1548 & 1540.5 & 1544.5 \\
\hline Production $(\mathrm{MWh} /$ year $)$ & 220.6 & 801.2 & 1408 \\
\hline
\end{tabular}

\subsection{OPEX calculation and estimation of $L C O E$}

\subsubsection{OPEX calculation}

The economic valuation of the maintenance depends on the country of installation of the plant, the proximity to urban centers, the annual fouling, and the existing monitoring system. However, for valuations to estimate the plant's LCOE, its calculation can be approximated to $0.5 \%$ of the annual CAPEX in plants intended for large-scale generation and $1 \%$ of the CAPEX in plants for self-consumption [11]. In the cases studied, the following estimate will be made, recommended by the NREL:

\section{OPEX annual=0,01·CAPEX}

\subsubsection{LCOE calculation}

The calculation of the LCOE can be carried out through the following expression, which is nothing more than an extension of the equation commonly used and including the losses due to degradation of the modules.

$$
L C O E\left(\frac{€}{M W h}\right)=\frac{\sum_{t=1}^{n} \frac{C A P E X+O P E X}{(1+r)^{t}}}{\sum_{t=1}^{n} \frac{\text { Production year } 1 \cdot(1-a)^{t}}{(1+r)^{t}}}
$$

For the LCOE simulation, the following values will be used: 
- CAPEX: the cost of the photovoltaic plant in absolute terms. It is obtained from the price of the EPC by adding a $4 \%$ surcharge for building licenses.

- OPEX: the cost of annual maintenance in absolute terms, approximated according to the NREL at $1 \%$ of CAPEX (taking into account that maintenance does not imply a cost in building licenses).

- Production year 1: values extracted from the simulation carried out.

- $\mathrm{r}$ : discount rate. As it is a facility intended for self-consumption, this value is quite high since the risk associated with a location change, a decrease in consumption, or other problems related to the company's future that owns the facility is high. A value of $6 \%$ will be used, which is between 4 and $8 \%$ recommended by Solar Bankability [12] and coincides with the values recommended by the NREL [13].

- a: loss of annual performance of the modules. The $0.7 \%$ guaranteed by the manufacturer in the characteristics of the equipment will be used.

- n: useful life of the plant will be considered 30 years [13].

\subsection{Numerical modeling of the LCOE}

The LCOE depends on a series of parameters that have been described in previous sections, and that in any case are known before the design of the installation, so the calculation of the LCOE can be modeled based on these data, allowing to see a guide value for an available area.

Therefore, obtaining the LCOE will be achieved as a consequence of the modeling of the variables that feed it. In the calculation method outlined in the Results section, an attempt will be made to guide values to work with the models in the event that some values are unknown.

The variables to be modeled are, in this order:

1. Peak power of the installation:

$$
P p(k W p)=f\left[A\left(m^{2}\right), \propto\left(^{\circ}\right), \eta_{p}(\%)\right]
$$

Where,

Pp: peak power of the installation, in $\mathrm{kWp}$.

A: available area on the roof, in $\mathrm{m} 2$

$\propto$ : module inclination, in degrees

$\eta_{\mathrm{p}}$ : performance of the module, which can be obtained directly from the technical data sheet of the equipment, and which can also be obtained from the power of the module and its area.

2. Yield of the installation:

$$
\text { Yield }\left(\frac{k W h}{k W p}\right)=f\left[G H I\left(\frac{k W h}{m^{2}}\right), \propto\left(^{\circ}\right), \text { location }\right]
$$

Being: GHI: Radiation in the Horizontal Plane in $\mathrm{kWh} / \mathrm{m} 2$. location: Situation of the installation.

3. Installation CAPEX and OPEX

$$
\operatorname{CAPEX}(€)=f\left[\operatorname{Pp}(k W p), \operatorname{Pmodule}\left(\frac{€}{W p}\right), \operatorname{Pinv}\left(\frac{€}{W p}\right), \operatorname{Pest}\left(\frac{€}{W p}\right), M B(\%)\right]
$$


Where,

Pmodule: module cost in $€ / \mathrm{Wp}$.

Pinv: inverter cost, in $€ / \mathrm{Wp}$. If only the cost of the inverter is known, an undersizing of $80 \%$ of the inverters with respect to the modules can be assumed, so it would be obtained from the expression: Powerinv $(\mathrm{Wn})=0,8^{*}$ Powermod $(\mathrm{Wp})$.

Pest: cost of structures provided by the manufacturer

$\mathrm{MB}(\%)$ : Gross Margin of the plant, in \%.

Given the variability of the market for modules, inverters, and structures, their value will be based on the $€$ / Wp ratio of these teams, which is how the sector usually works. In addition, the rest of the costs will be modeled based on the peak installed power for reasons of economy of scale since significant variations cannot be expected from these costs. The OPEX, due to its little relevance concerning the CAPEX, will remain as $1 \%$ of the annual CAPEX.

4. LCOE of the installation:

$\operatorname{LCOE}\left(\frac{€}{M W h}\right)=f[\operatorname{CAPEX}(€), O P E X(€), \operatorname{Production}(M W h), L(\%), r(\%), a(\%), n($ year $)]$

Where,

L: cost of the building license compared to the cost of the EPC (\%)

$\mathrm{r}$ : discount rate $(\%)$

a: annual performance loss of the modules.

n: useful life of the plant.

2.5.1 Numerical modeling of peak power

For the generation of a numerical model that predicts the installed power of a plant based on the variables collected in Equation (3), the following analytical expression can be reached:

$$
P p(W p)=n^{\circ} \text { modules } \cdot P_{\text {module }} \rightarrow P p(W p)=n^{\circ} \operatorname{modules} \cdot A_{\text {module }} \cdot \eta_{p} \cdot G
$$

$\mathrm{G}$ is the radiation value for evaluating the module's performance under STC conditions of $1000 \mathrm{~W} / \mathrm{m}^{2}$.

The peak power only depends on the area of installed modules and their performance and is independent of the dimensions of the module, since an increase in size leads to a proportional reduction in the installed modules.

Therefore, we are left with expression (8):

$$
P p(k W p)=A_{\text {modules }}\left(m^{2}\right) \cdot \eta_{p} \cdot G\left(\frac{k W p}{m^{2}}\right)
$$

With the results collected from the different simulations carried out, an expression can be generated that predicts the installable module area based on the surface area and the inclination to be given to the modules. The Module Area / Useful Area ratio will be modeled for the cases of the $12000 \mathrm{~m}^{2}$ area, which will have lower distortions due to module removal. This ratio can be modeled with a second-degree numerical function. The area of the modules is a function of the useful area of the roof and its inclination, and can be calculated with the expression:

$$
\text { Amodule }=A \cdot\left(1,75 \cdot 10^{-4} \cdot \alpha^{2}-0,0175 \alpha+0,826\right)
$$


Combining expressions (8) and (9), the numerical model is obtained that predicts the peak power of the photovoltaic installation based on the previously mentioned variables. The $G$ is multiplied directly by the constants of Expression (9) to simplify the expression:

$$
P p=A \cdot \eta_{p} \cdot\left(0,175 \cdot \alpha^{2}-17,5 \alpha+826\right)
$$

The error generated by this expression has been calculated by predicting the 120 simulations carried out. The mean error of the expression is $3.7 \%$, mainly due to eliminating modules to adjust the number of modules per string in roofs with a smaller area. The calculation of the error generated by the model is detailed in the Results section.

\subsubsection{Numerical modeling of YIELD}

Obtaining the Yield for the installation not only depends on the radiation in the horizontal plane and the inclination of the modules, but also deviations are expected depending on the location of the modules within the national territory, as shown in Expression (4).

Four numerical models have been created, one for each of the simulated locations. So that the results can be adapted to the Global Horizontal Irradiation of each particular location, the result has been maintained based on this parameter.

Variations in module technology, inverters, and even the presence of step-up transformers influence plant performance. However, the model will be simplified not considering these variables:

The effect of module technology was very relevant in equipment manufactured at the beginning of the decade. However, in the latest technology equipment the differences between monocrystalline and polycrystalline modules are very small. In the total of the simulations carried out, the accumulated difference is less than $0.1 \%$.

The effect of the inverter technology depends on the approach in the distribution of strings and the number of MPPT of the inverter. The variation from one model to another is also relevant. In any case, the gain of having multi MPPT systems compared to inverters with a single MPPT is less than $2 \%$. [14]

The transformers do not present losses of more than $1 \%$, so their presence can be considered that they do not significantly affect the plant's production.

Therefore, the expressions that allow obtaining the Yield of the plant as a function of the GHI value and the selected inclination, for a given plant, result:

$$
\begin{aligned}
& \text { Center },\left(\text { Madrid): Yield }=\text { GHI } \cdot\left(-1,119 \cdot 10^{-4} \cdot \alpha^{2}+7,752 \cdot 10^{-3} \cdot \alpha+0,8552\right)\right. \\
& \text { North }(\text { Bilbao }): \text { Yield }=\text { GHI } \cdot\left(-1,295 \cdot 10^{-4} \cdot \alpha^{2}+7,567 \cdot 10^{-3} \cdot \alpha+0,8546\right) \\
& \text { South }(\text { Seville }): \text { Yield }=\text { GHI } \cdot\left(-1,309 \cdot 10^{-4} \cdot \alpha^{2}+8,083 \cdot 10^{-3} \cdot \alpha+0,8352\right)
\end{aligned}
$$

Canaries (Lanzarote): Yield $=$ GHI $\cdot\left(-8,67 \cdot 10^{-5} \cdot \alpha^{2}+4,625 \cdot 10^{-3} \cdot \alpha+0,8648\right)$

\subsection{3 numerical modeling of CAPEX and OPEX}

As previously mentioned, the numerical modeling will be based on the costs in $€$ / Wp of modules, inverters, and structures, since their price fluctuates a lot in the market. The rest of the costs of a plant are more linked to the number of modules of the plant than to its power, since the costs associated with the same number of monocrystalline and polycrystalline modules are similar. That is why the cost of the rest of the low voltage elements has been calculated for the cases studied, and a potential regression has been 
generated that represents the cost variation in $€$ / Module as a function of the number of modules.

In the generation of the previous graph, the cost of the CT has been discounted, to include only the costs that would be expected in low voltage. If the presence of a transformation center is necessary to increase tension, its price should be considered separately.

On the other hand, in the case of using modules of 60 cells, which are proportionally smaller and less powerful than the modules of 72 cells, the expression will have to be corrected with a correction factor.

Therefore, the equation developed that allows calculating the sale price of a photovoltaic installation results:

$$
\operatorname{CAPEX}(€)=\frac{1000 \cdot[\text { Pmodule }+ \text { Pinv }+ \text { Pest }] \cdot P p+439,9 \cdot N \bmod \cdot(\mathrm{fc} \cdot \mathrm{Nmod})^{-0,259}+A T}{(1-M B)}
$$

Where,

Pmodule: Module cost, in $€ / W p$.

Pinv: Inverters' cost, in $€ / \mathrm{Wp}$

Pest: Structures cost, in $€ / \mathrm{Wp}$

Pp: Total peak power of the installation, calculated in step 1.

fc: Correction factor. Values:

60-cell modules, $\mathrm{fc}=5 / 6$

72-cell modules, $\mathrm{fc}=1$

This correction factor allows that in the plant's final cost, it is considered that the 60 cell modules present less power. Therefore, the cost of wiring, grounds, and protections that they entail is proportionally lower than the 72-cell modules.

Nmod: number of modules of the plant, calculated by clearing expression (7).

AT: cost of the voltage raising system if necessary

MB: gross margin of the facility, office costs, and industrial profit. $12 \%(6 \%+6 \%)$ is proposed as a reference value

The OPEX is obtained directly from Expression (1).

Section 7 contains the procedure to calculate the installation cost with the suggestion of values in case any variable is unknown.

2.5.4 Numerical modeling of the LCOE

The calculation of the LCOE for the case of photovoltaic energy is translated into Equation (2). When developing a numerical model, the complication is that this equation is decomposed into a set of elements in both summations of the expression, so its calculation cannot be developed quickly.

However, some expressions simplify the calculation, generating an error associated with the value of the discount rate. The developed equation has a capital recovery factor, CRF, which corrects the depreciation effect over time caused by the discount rate. This CRF has the expression $[15,16]$ :

$$
C F R=\frac{r(1+r)^{n}}{(1+r)^{n}-1}
$$

Multiplying this factor by the elements of the equation that enter the cash flow in year 0 (CAPEX) The following expression is generated: 


$$
\operatorname{LCOE}\left(\frac{€}{M W h}\right)=\frac{(1+L) \cdot \frac{r(1+r)^{n}}{(1+r)^{n}-1} \cdot \operatorname{CAPEX}(€)+\text { OPEX }\left(\frac{€}{\text { year }}\right)}{\text { Production }_{\text {year } 1}(M W h)}
$$

Where $\mathrm{L}$ is the cost of the building license with respect to CAPEX, $\mathrm{r}$ the discount rate, and $\mathrm{n}$ the years of the useful life of the installation.

The following approximation has been made:

$\mathrm{a}=0$

In other words, the effects of the degradation of the modules are not considered. This simplification increases the precision of the model since the tendency for high discount rates is to give LCOE values higher than the expected value. Therefore, eliminating the effect of the degradation of the modules in the equation, the values predicted by the model are closer to the real values.

\section{Results and discussion}

3.1. Installable power analysis

Figure 4 shows the installable power for each of the 30 simulated installations obtained from the results of the Helioscope software.

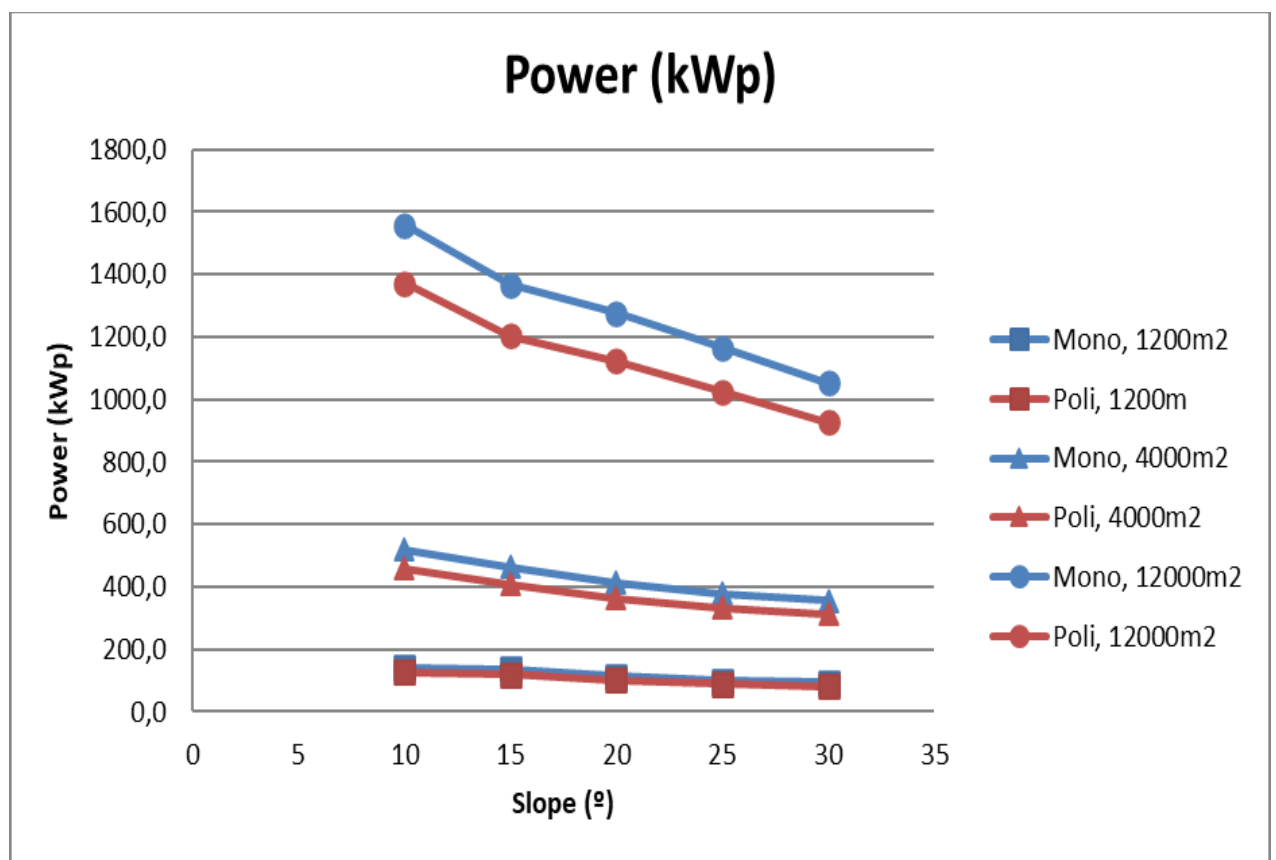

Figure 4. Installed power as a function of module inclination and surface available

As can be seen, an increase in the inclination causes a decrease in the installable power for flat roofs, since it is necessary to increase the space between rows of modules.

Figure 5 shows the percentage of installable power over the maximum, with $100 \%$ being the maximum installable power for a $10^{\circ}$ inclination. The results are only collected for the case of monocrystalline installations with an area of $12000 \mathrm{~m}^{2}$, but the result can be extrapolated to other cases. 


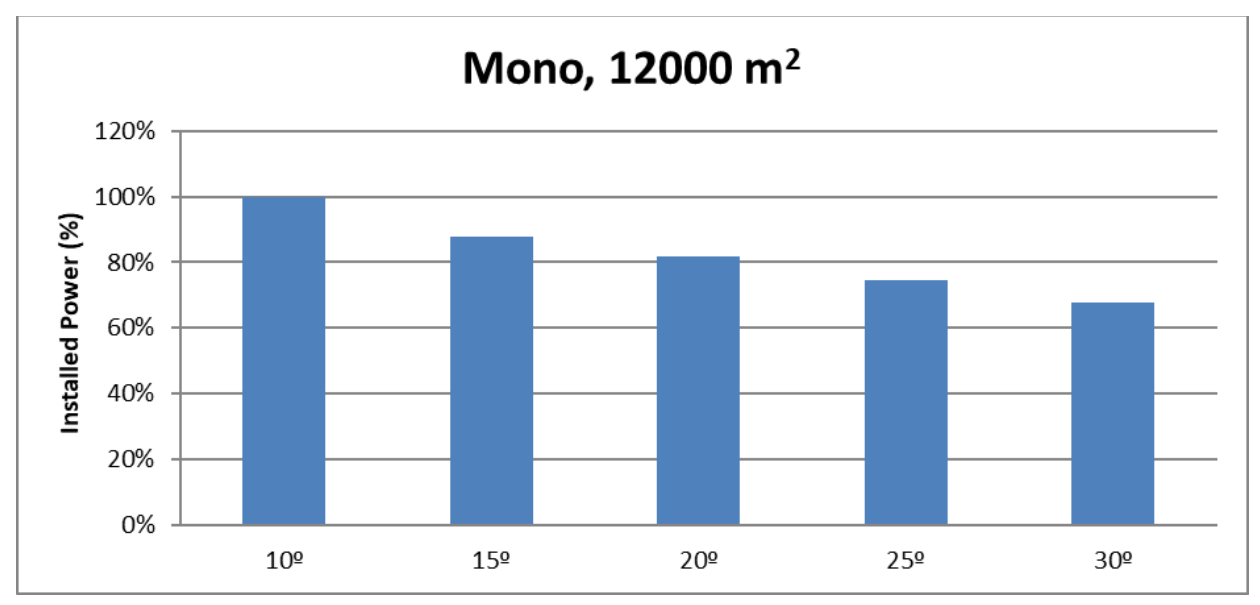

Figure 5. Installed capacity as a function of module inclination

Tilting the modules at $30^{\circ}$ means that only $68 \%$ of the installable power can be installed with a $10^{\circ}$ slope. The maximum power that can be installed is directly proportional to the performance of the module. Switching to $375 \mathrm{Wp}$ monocrystalline modules instead of $330 \mathrm{Wp}$ polycrystalline modules implies an increase in power of $14 \%$. Finally, an increase in the area implies a directly proportional increase in the maximum installable power since proportionally more modules fit.

\subsection{Yield analysis}

The Yields depend directly on the Global Horizontal Irradiation of the location, which is the energy that reaches the horizontal plane per unit area in a calendar year. Figure 6 shows the GHI for each of the studied sites:

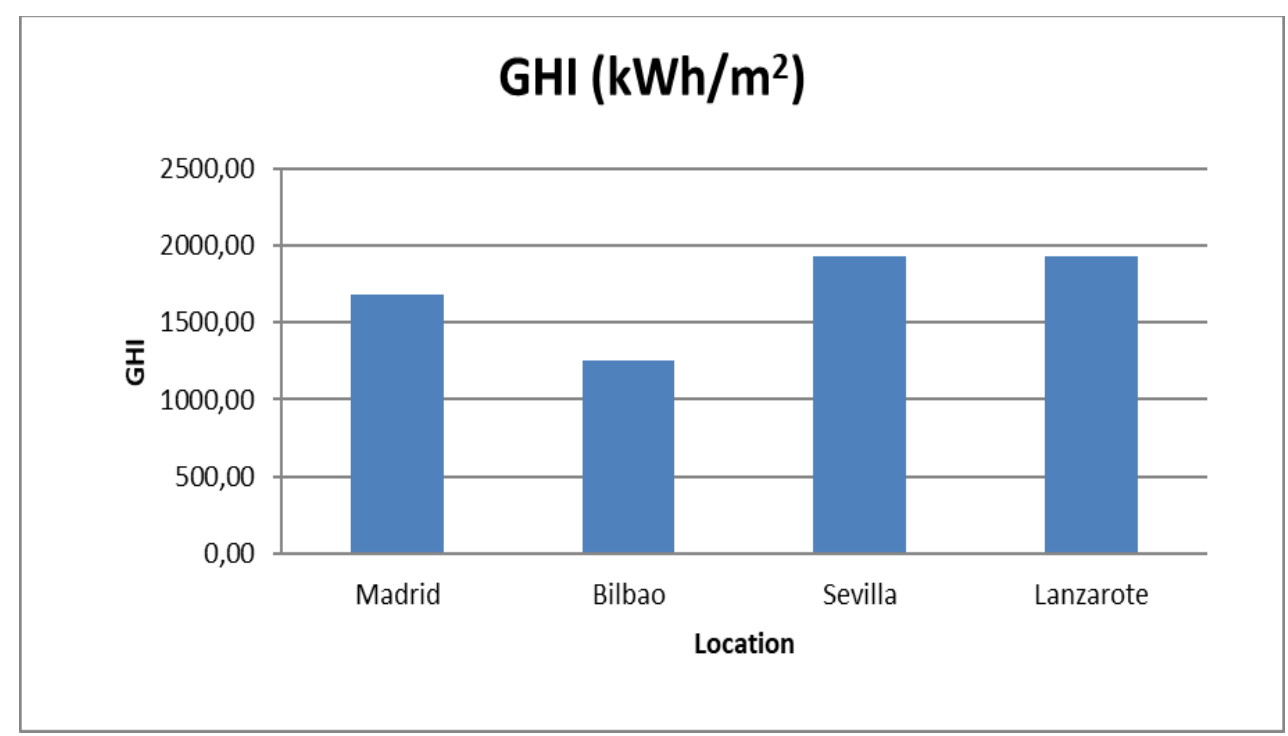

Figure 6. GHI for each of the studied locations

As shown in Figure 6, the GHI is lower in the North of the peninsula than in the South. This is because the Sun has a higher trajectory throughout the year, which increases the projection concerning the horizontal. On the other hand, the less cloudy weather in the locations increases the GHI considerably. By latitude, Lanzarote should have a higher GHI. In this case, this increase in the hours of the Sun is not translated into radiation due to its weather. On the one hand, it indeed has less rainfall than Seville, but on the other hand, if we analyze cloudy and partially cloudy days, the proportion is considerably higher than in Seville (only 73.6 days a year are considered completely sunny in Lanzarote, compared to 193.2 in Seville) [17]. 
Figure 7 shows the variation of Yield as a function of the inclination for each of the studied locations, collecting the results of the $1200 \mathrm{~m} 2$ installations with monocrystalline modules:

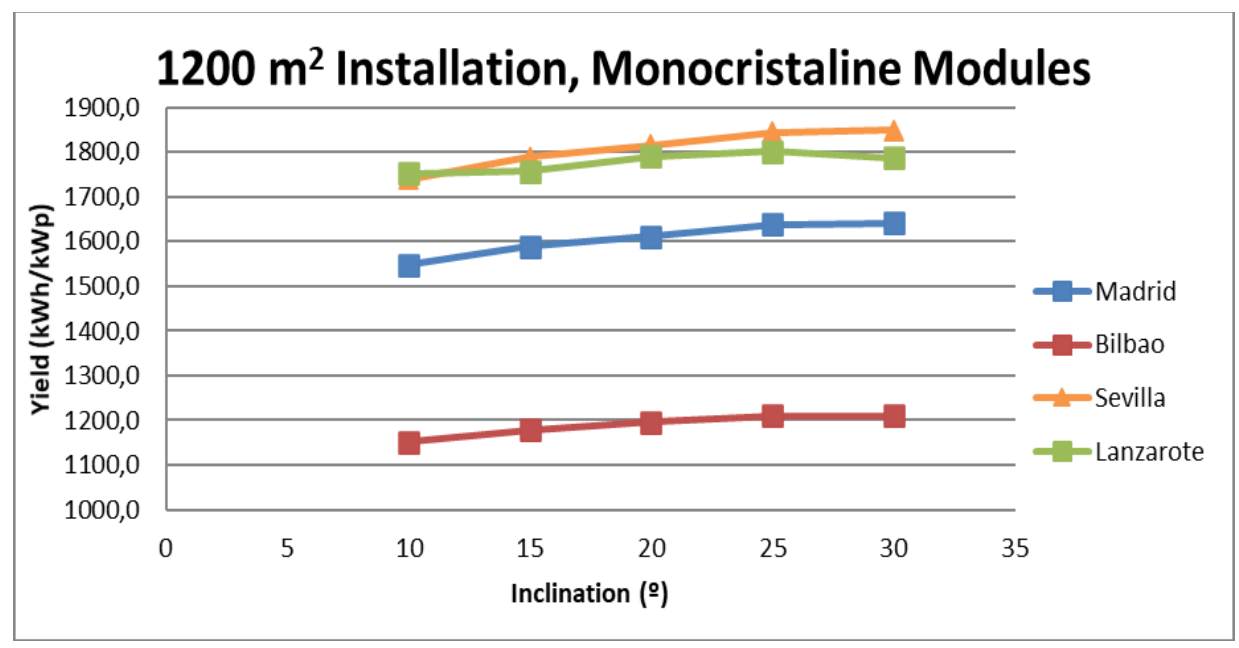

Figure 7. Yield as a function of inclination for each of the studied locations

The maximum production is found in those locations with the higher GHI, since it is the main parameter that affects photovoltaic production. Figure 8 shows the increase in Yield compared to the base case of $10^{\circ}$ for monocrystalline facilities with an area of $1200 \mathrm{~m} 2$. This figure is presented to show in more detail the effect of module inclination on production.

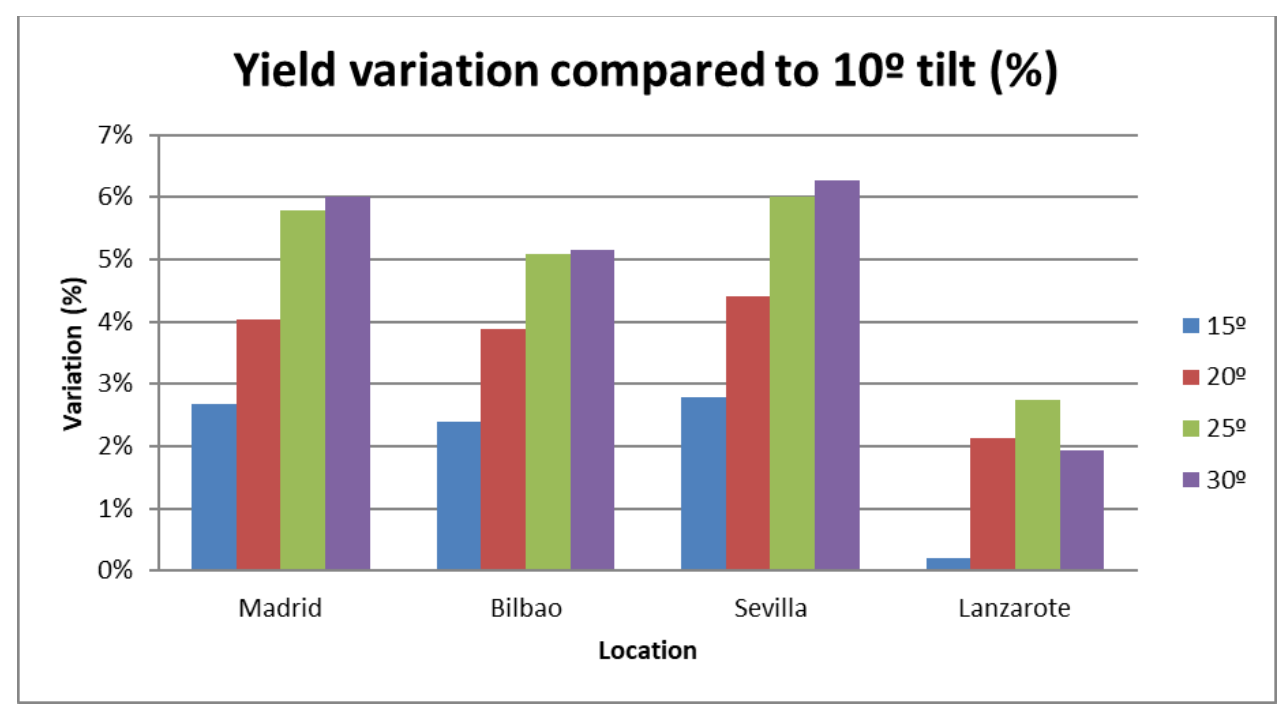

Figure 8. Variation of the Yield with respect to $10^{\circ}$ for the studied locations

As shown in Figure 8, in peninsular locations, the maximum production is obtained with slopes of around $30^{\circ}$, achieving a gain of between $5 \%$ and $6 \%$ compared to the $10^{\circ}$ installation. Slopes of less than $10^{\circ}$ are not considered recommended as they favor the accumulation of dirt. Furthermore, the gain is especially relevant when increasing the inclination from slightly inclined arrangements (from $0^{\circ}$ to $10^{\circ}$, the gain is around $8 \%$ for all cases, according to Helioscope reports). Still, the difference between $25^{\circ}$ and $30^{\circ}$ is practically negligible in peninsular cases. This behavior is perfectly described by means of a second-degree polynomial equation with a maximum of around $30^{\circ}$, as can be seen in equations (11-14). In Lanzarote (Canary Islands), which is in a considerably more southern location, the variation in production with inclination is very small, and only gains are 
achieved compared to $10^{\circ}$ of less than $3 \%$. Furthermore, in this case, the optimum inclination is less than $25^{\circ}$. Figure 9 shows the variation of the mean PR for the two types of modules studied in the $1200 \mathrm{~m} 2$ facilities:

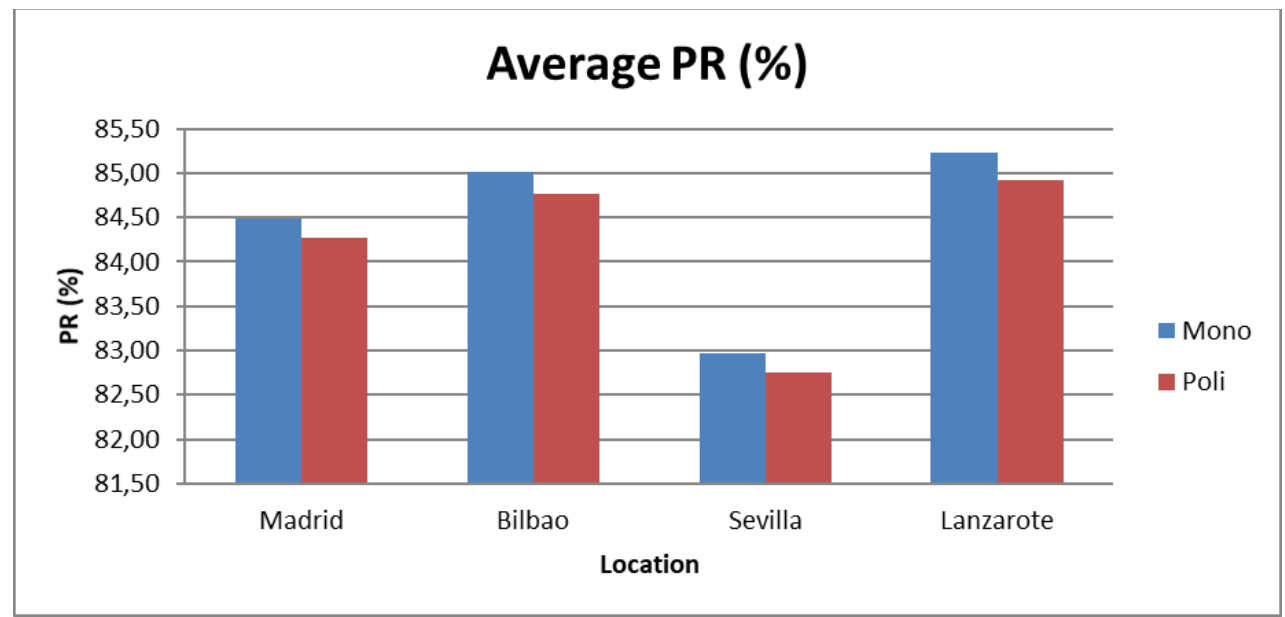

Figure 9. Average PR for each of the studied locations

The PR for monocrystalline module installations is generally higher than for polycrystalline installations. In general, facilities with a monocrystalline module tend to have a worse PR, due to the worse behavior that the modules have with higher temperature. However, the fact of having PERC monocrystalline modules makes it possible to reverse this situation. PERC cells prevent unused radiation from being absorbed by the metal contact of the frame, allowing this radiation to reflect and pass through the cell again. In the case of the polycrystalline cells used, which do not have this technical improvement, the absorption of radiation by the frame heats the modules, which causes a decrease in production, this effect is attenuated in the case of cells with PERC technology.

\subsection{CAPEX analysis}

To make an adequate comparison of how the different variables affect the CAPEX of the plant, both the effects on the total CAPEX (in this case, not including the building license) and the normalized CAPEX per installed peak watt have been analyzed. Figure 10 shows the cost of normalized CAPEX per installed peak watt.

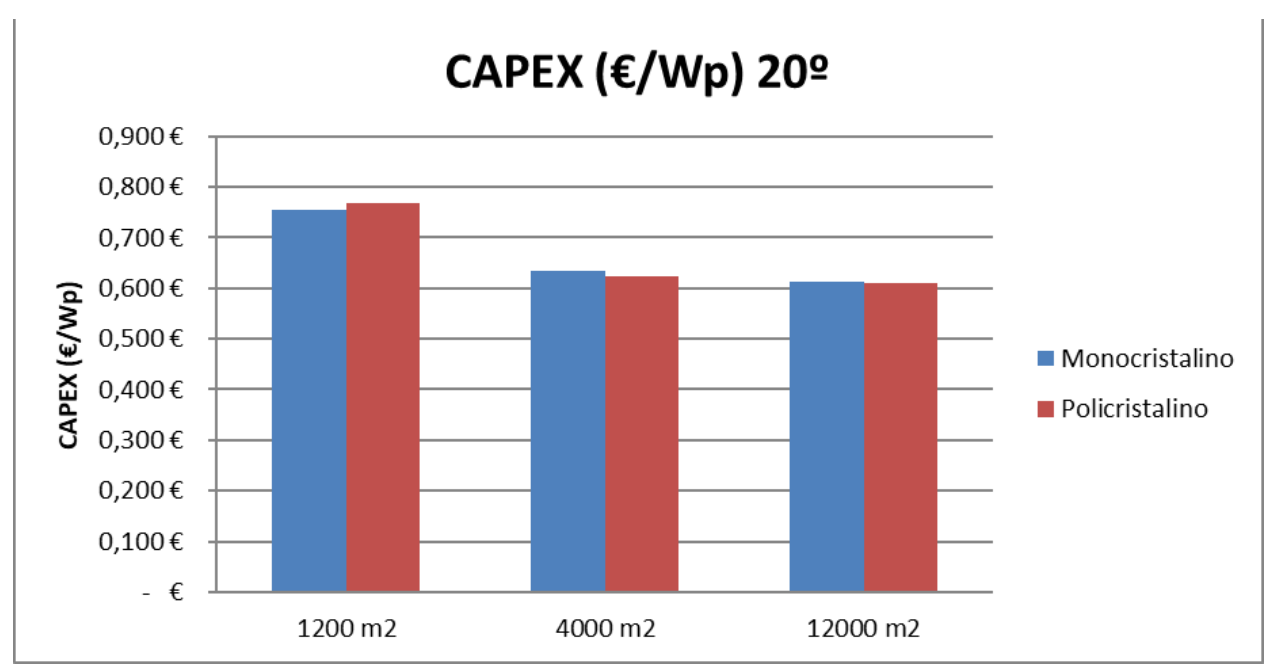

Figure 10. Normalized CAPEX for installations with a tilt 
For economies of scale, an increase in the available area (and, therefore, the installed power) causes a decrease in the cost per installed peak watt. In this case, two effects can be observed. On the one hand, in lower power installations, the economy of scale and the importance of structural costs make monocrystalline modules the best alternative in small installations. On the other hand, the difference between the studied facilities with an area of 4,000 $\mathrm{m}^{2}$ and the facilities of $12,000 \mathrm{~m}^{2}$ are less significant, mainly due to the costs of the high voltage transforming system, which distort the effects of the economy of scale. Figure 11 is expanded with all the cases studied.

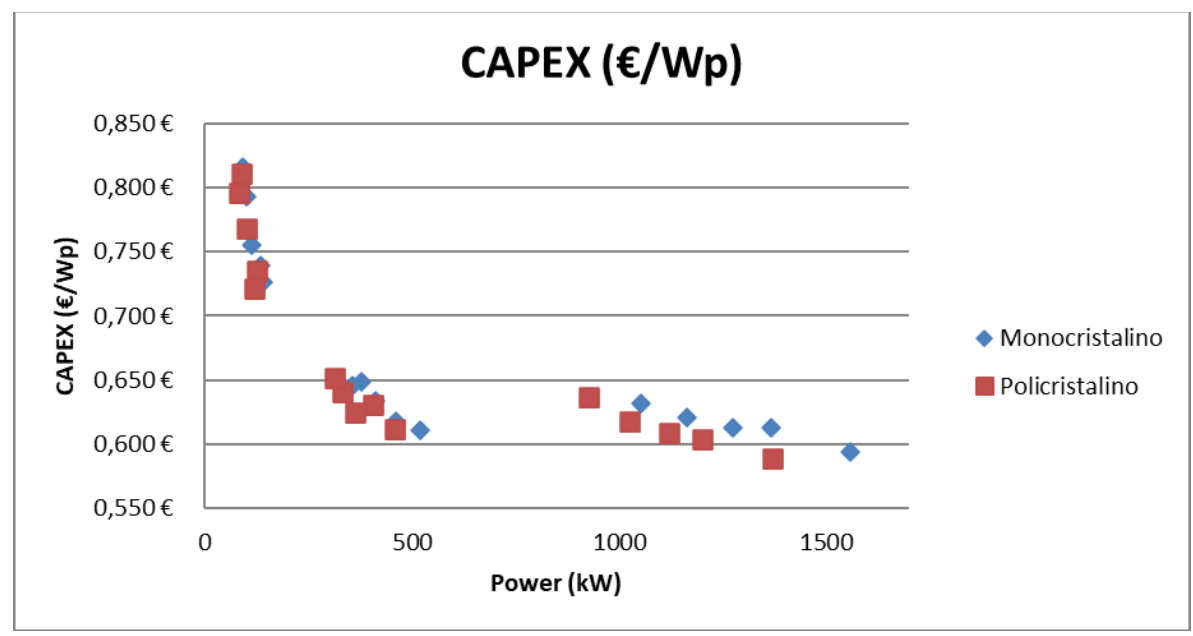

Figure 11. Normalized CAPEX as a function of installed capacity

As can be seen, the standardized cost of the installation decreases with power, although in plants in which the voltage elevation system has been considered (areas of $12,000 \mathrm{~m}^{2}$ ), there is an increase in costs for the transformation center. It is important to bear in mind that the usual thing for more than $700 \mathrm{kWp}$ is to inject into the medium voltage network since it is not usual to find a module that consumes this power in low voltage continuously. Table 4 shows the costs of the main equipment of the installations with $20^{\circ}$ inclination:

Table 4. Normalized costs for installations with $20^{\circ}$ inclination

\begin{tabular}{|l|c|c|c|c|c|}
\hline \multicolumn{1}{|c|}{ Case } & $\begin{array}{c}\text { Module } \\
(€ / \mathrm{Wp})\end{array}$ & $\begin{array}{c}\text { Inverter } \\
(€ / \mathrm{Wp})\end{array}$ & $\begin{array}{c}\text { Structure } \\
(€ / \mathrm{Wp})\end{array}$ & $\begin{array}{c}\text { Assembly } \\
(€ / \mathrm{Wp})\end{array}$ & $\begin{array}{c}\text { Other } \\
(€ / \mathrm{Wp})\end{array}$ \\
\hline $1200 \mathrm{~m}^{2}-$ Mono & 0.290 & 0.063 & 0.086 & 0.086 & 0.231 \\
\hline $1200 \mathrm{~m}^{2}-$ Poli & 0.250 & 0.072 & 0.097 & 0.097 & 0.251 \\
\hline $4000 \mathrm{~m}^{2}-$ Mono & 0.275 & 0.053 & 0.073 & 0.073 & 0.159 \\
\hline $4000 \mathrm{~m}^{2}$ - Poli & 0.240 & 0.050 & 0.083 & 0.083 & 0.169 \\
\hline $12000 \mathrm{~m}^{2}-$ Mono & 0.265 & 0.042 & 0.072 & 0.072 & 0.163 \\
\hline $12000 \mathrm{~m}^{2}-$ Poli & 0.230 & 0.043 & 0.081 & 0.081 & 0.174 \\
\hline
\end{tabular}

Different aspects can be analyzed from this table. On the one hand, the costs included representing the effect of the economies of scale of the equipment. In small installations, the modules are received directly from warehouses within the peninsula, so the cost is more expensive. For larger sizes, shipments are made directly from China, which lowers the cost of intermediaries. In inverters, the price per installed peak watt is lower for larger plants, especially since more powerful equipment is used, and it is cheaper. 
Both assembly and structure of work represent the effects of economies of scale, and the assembly of monocrystalline modules is more economical. This second effect is because the cost is the same for the same number of modules, but in monocrystalline modules, it is distributed over a higher power. The rest of the costs are much higher for small installations (the execution of the project requires many more hours per installed module and the fact that there are many expenses that are independent of the power of the plant. This cost increases from the surfaces of $4000 \mathrm{~m}^{2}$ to $12000 \mathrm{~m}^{2}$, but this is due solely to the cost of the Transformation Center.

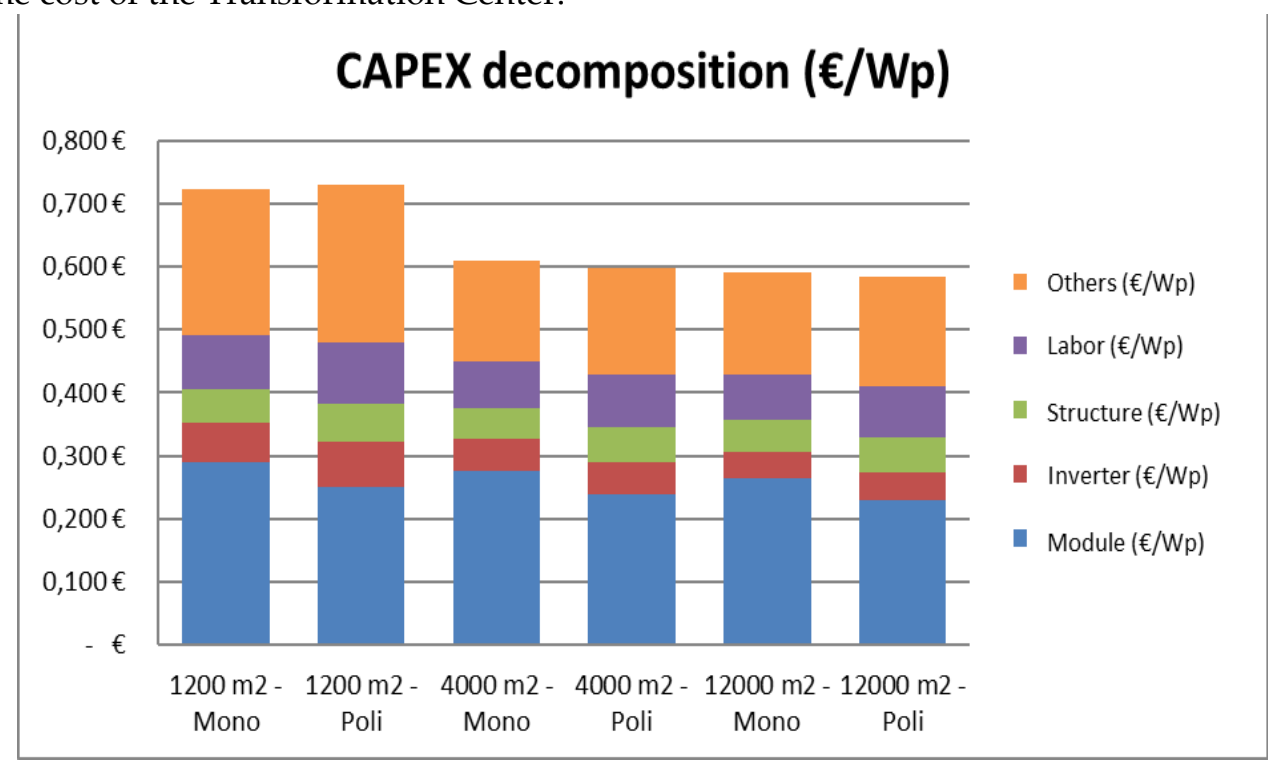

Figure 12. Normalized CAPEX decomposition

As shown in Figure 12, the cost of the modules continues to account for most of the cost of photovoltaic installations (on average $40 \%$ ). However, its lower cost compared to previous years has generated that the rest of the costs are more and more decisive. Therefore, the optimization of these expenses plays a fundamental role in the competitiveness of the current installers and developers.

\subsection{LCOE analysis}

The CAPEX, OPEX, and production calculated for the photovoltaic installations studied have been used to calculate the LCOE of the different cases. Figure 13 shows the range of values obtained for each of the locations of the 30 cases studied, considering a discount rate of $6 \%$ and a useful life of 30 years.

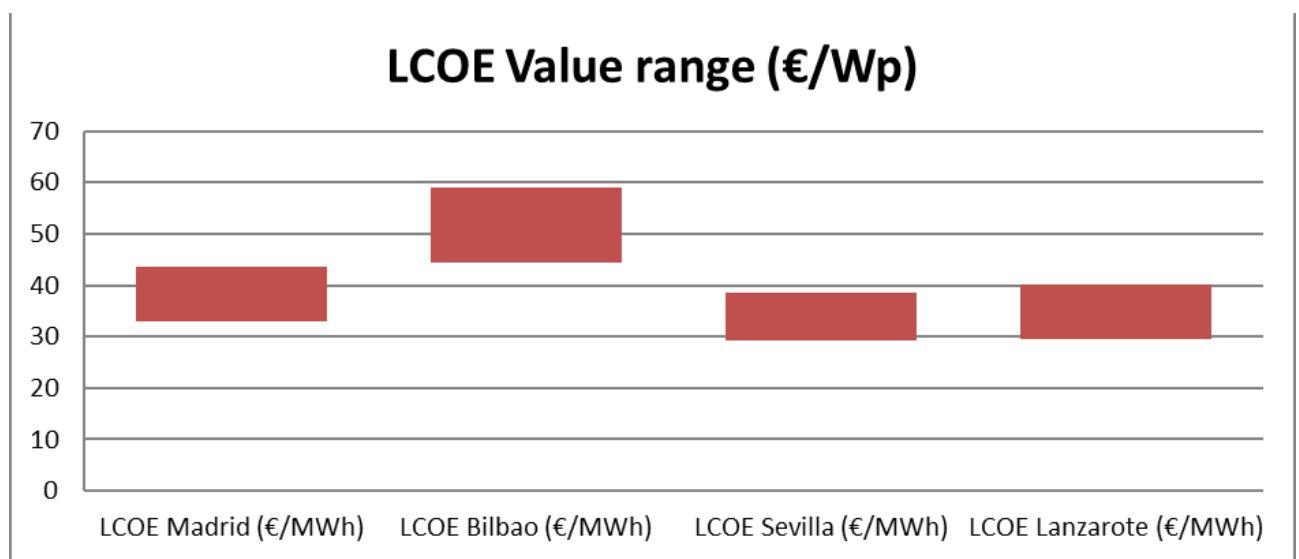

Figure 13. LCOE value range for each of the locations studied 
As can be seen in the previous graph, the LCOE obtained depends to a great extent on the location of the plant since the variation of the available resource is very important from one location to another. On the other hand, there are variations in the LCOE of up to $25 \%$ within the same location depending on the rest of the variables studied. Figure 14 shows the results for the case of Madrid with an inclination of $20^{\circ}$.

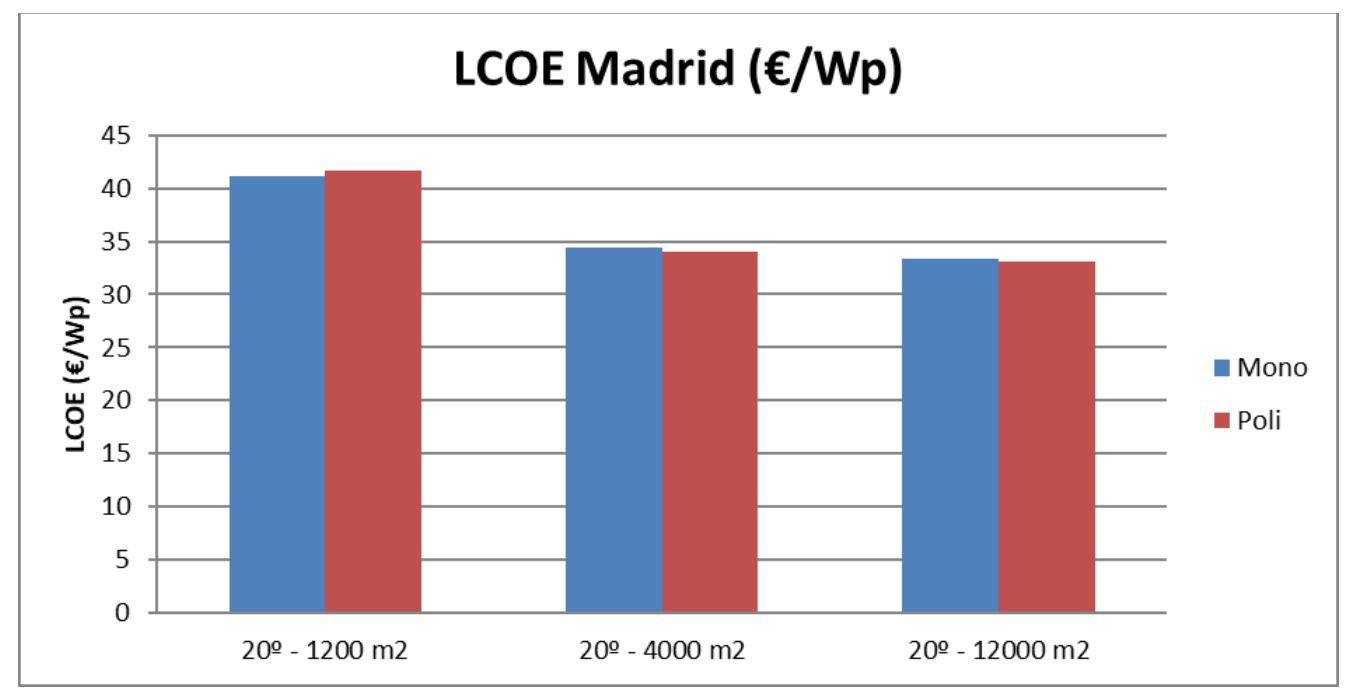

Figure 14. LCOE in Madrid for installations with an inclination of $20^{\circ}$

The reduction in CAPEX $(€ / \mathrm{Wp})$ generated by a larger size of the plant has a significant impact on the LCOE obtained. Furthermore, it can be seen that with the module prices considered, the difference between installations with monocrystalline modules and those with polycrystalline technology is minimal. In smaller plants, plants with monocrystalline modules have a lower LCOE, since the impact of the economy of scale is greater. Therefore, the increase in installed power caused by monocrystalline technology can offset the higher cost of the module. For larger plants, a lower LCOE is generally observed in polycrystalline module installations. The results obtained for the different inclinations studied are represented below:

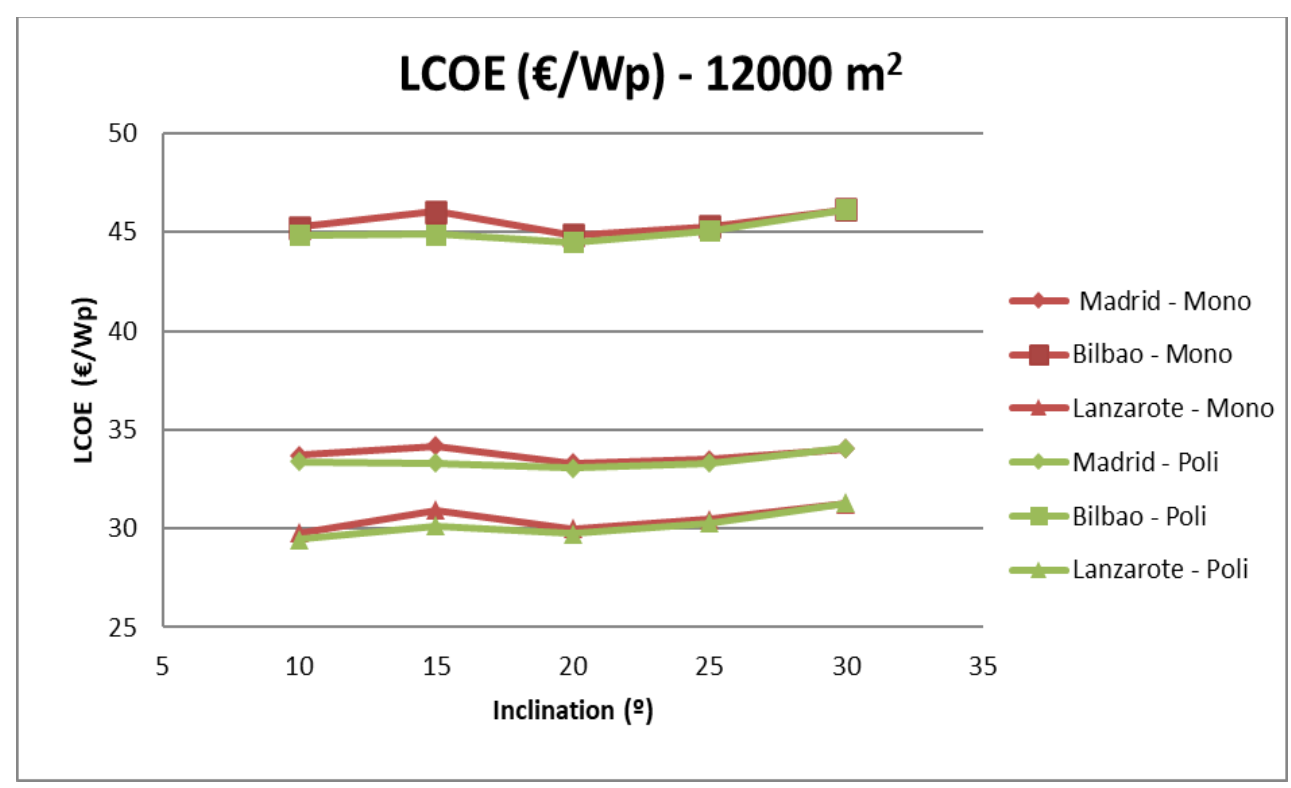

Figure 15. LCOE variation as a function of inclination 
It can be observed that the greater inclination of the modules, which causes an increase in the Yield of the plant, conflicts with the greater CAPEX per Wp generated by issues of economy of scale (the greater the inclination, the greater the separation, and therefore the lower available power). This means that, contrary to the usual recommendations to plan an installation with an inclination that optimizes the Yield, it is better to find the best approach by calculating the LCOE of the different alternatives. The high reduction in the price of the modules in recent years has caused the other costs studied to be increasingly important, so the best solution will not necessarily coincide with the inclination of higher production per installed watt. It compensates for increasing the power at the cost of sacrificing part of the Yield. In those cases, the lowest LCOE is obtained in installations with an inclination of $10^{\circ}$ in Lanzarote and $20^{\circ}$ in the rest of the locations, different from the $30^{\circ}$ that is recommended to maximize the Yield.

Figure 16 studies the influence of the economic variables considered for the Madrid facilities (monocrystalline module, $10^{\circ}$, surface of $1200 \mathrm{~m}^{2}$ ):

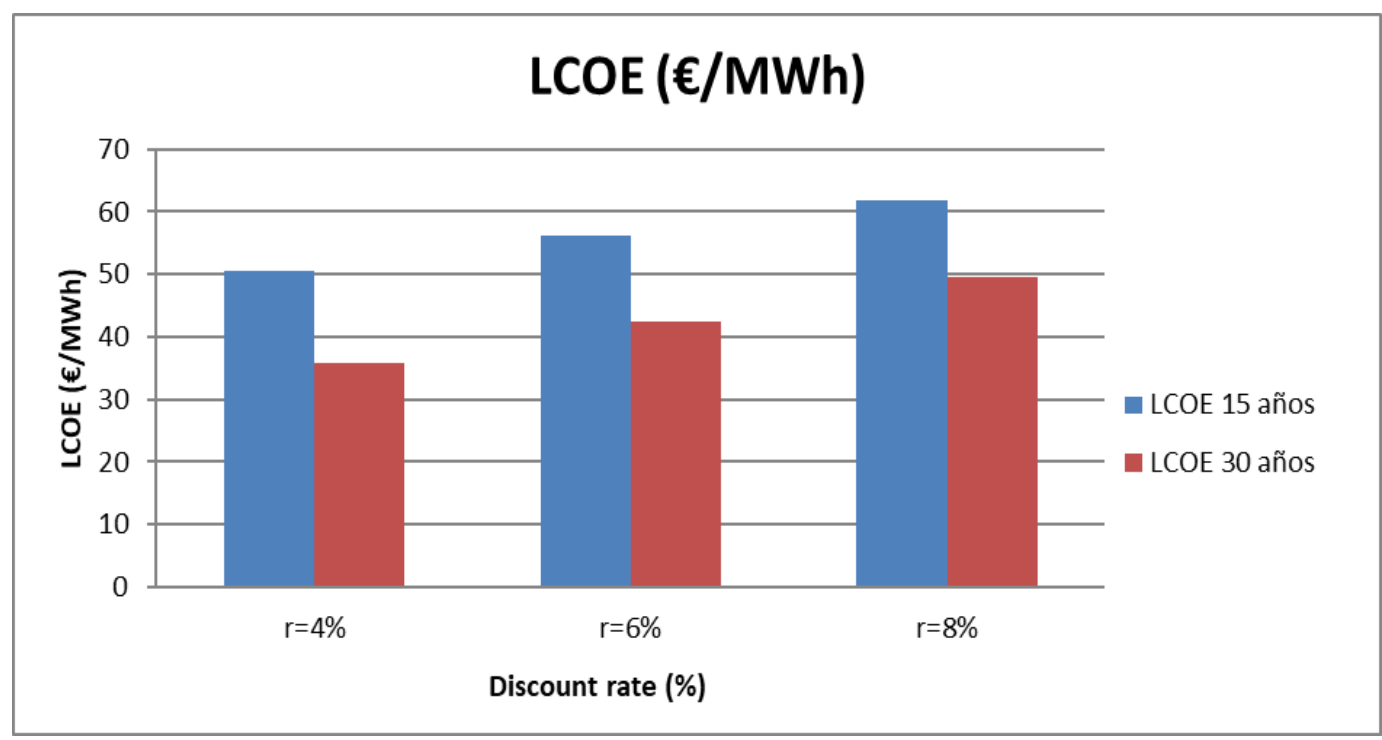

Figure 16. Variation of LCOE as a function of the discount rate and the years of useful life considered

As can be seen, the discount rate considered is a variable of great importance for calculating the LCOE of the facilities, since it depreciates the value of production progressively over the years. The installation's lifetime is also essential when calculating the LCOE of the facilities because the cost is the same. Still, this expense is spread over a greater number of years of use.

\section{Procedure developed for the LCOE calculation}

4.1 Procedure compilation

As a result of the calculation developed in Section 2.5, an estimate of the LCOE of a flat roof photovoltaic plant can be made that meets the following requirements:

Plant located in Spain.

Flat roof on which the modules will lean.

Injection system 0 .

The useful surface of the roof limits the design power and not the customer's consumption.

If the target power for customer consumption reasons is lower than the power obtained in Section 2 (in which the limiting factor is area), it is recommended to continue directly in step 2 with the target power since it will be the most restrictive design criteria.

Step 1. Installed peak power estimate 
The peak installed power can be obtained through the following expression:

$$
P p(k W p)=A \cdot \eta_{p} \cdot\left(0,175 \cdot \alpha^{2}-17,5 \alpha+826\right)
$$

Where $A$ is the area of the roof in square meters; $\eta_{\mathrm{p}}$ is the performance of the selected modules under STC conditions and both by one, and $\alpha$ is the degree of inclination to be given to the modules.

The module's performance can be obtained from the technical sheet of the equipment to be used. As an example, some guideline values for modules of 72 cells are collected in Table 5:

Table 5. Expected performance for different types of modules

\begin{tabular}{|l|c|c|}
\hline \multicolumn{1}{|c|}{ Module } & Dimensions $(\mathrm{mm} \times \mathrm{mm})$ & $\eta_{p}$ \\
\hline $320 \mathrm{Wp}$, policristaline & $1960 \times 992$ & 16.5 \\
\hline $325 \mathrm{Wp}$, policristaline & $1960 \times 992$ & 16.7 \\
\hline $330 \mathrm{Wp}$, policristaline & $1960 \times 992$ & 16.9 \\
\hline $370 \mathrm{Wp}$, monocristaline & $1960 \times 992$ & 19.0 \\
\hline $375 \mathrm{Wp}$, monocristaline & $1960 \times 992$ & 19.3 \\
\hline
\end{tabular}

The performance of the module can also be obtained with the data of the peak power in STC conditions and its dimensions, through the expression:

$$
\eta_{p}=\frac{\text { Ppanel }(W p)}{1000\left(W / m^{2}\right) \cdot A m o d u l e\left(m^{2}\right)}
$$

Step 2. Calculation of the Yield and the generated production

The expressions that allow obtaining the Yield of the plant can be calculated for guidance only knowing the inclination of the modules, the location in which they are located and the GHI of this location. It can be estimated using one of the following expressions:

$$
\begin{aligned}
& \text { Zone 1: Yield }=\text { GHI } \cdot\left(-1.119 \cdot 10^{-4} \cdot \alpha^{2}+7.752 \cdot 10^{-3} \cdot \alpha+0.8552\right) \\
& \text { Zone 2: Yield }=\text { GHI } \cdot\left(-1.295 \cdot 10^{-4} \cdot \alpha^{2}+7.567 \cdot 10^{-3} \cdot \alpha+0.8546\right) \\
& \text { Zone 3: Yield }=\text { GHI } \cdot\left(-1.309 \cdot 10^{-4} \cdot \alpha^{2}+8.083 \cdot 10^{-3} \cdot \alpha+0.8352\right) \\
& \text { Zone 4: Yield }=\text { GHI } \cdot\left(-8.670 \cdot 10^{-5} \cdot \alpha^{2}+4.625 \cdot 10^{-3} \cdot \alpha+0.8648\right)
\end{aligned}
$$

With the Yield in $\mathrm{kWh} / \mathrm{kWp}$ and GHI in $\mathrm{kWh} / \mathrm{m} 2$ for one year. As the Yield not only depends on the GHI and the inclination but also depends on the effects of latitude and temperature, the Spanish State has been sectorized into four zones. Each zone can be considered as:

Zone 1: corresponds to the central zone of the Iberian Peninsula. It is applied in the communities of Castilla y León, Extremadura, the Community of Madrid, Castilla la Mancha, Valencian Community, and the Balearic Islands.

Zone 2: corresponds to the northern part of the peninsula, made up of Galicia, Asturias, Cantabria, the Basque Country, La Rioja, Navarra, Aragon, and Catalonia.

Zone 3: corresponds to the southern zone of the peninsula, made up of the communities of Andalusia, Murcia, as well as Ceuta and Melilla.

Zone 4: Canary Islands.

It is recommended to use data from weather stations close to the plant site. As a query, the ADRASE data (Access to Solar Radiation Data in Spain) can be used once converted to $\mathrm{kWh} / \mathrm{m}^{2}$.year [18]. 
The production generated in year 1 of the plant is calculated directly by multiplying the Yield (calculated in this step) by the installed power, obtained from step 2:

$$
\text { Annual Production }(k W h)=\text { Yield }\left(\frac{K W h}{k W p}\right) \cdot \text { Peak Power }(k W p)
$$

Step 3: Calculation of the CAPEX and OPEX of the plant

The calculation of CAPEX does not include the building license, which is generally paid by the owner of the project, and therefore its cost is considered in the calculation of the LCOE but not in the calculation of the cost of the installation. For the CAPEX assessment, it is necessary to calculate the number of modules in the installation, through the expression:

$$
\text { Nmodule }=\frac{\text { Peak Power }}{\text { STC Module Power }}
$$

The equation developed that allows estimating the sale price of a photovoltaic installation results:

$\operatorname{CAPEX}(€)=\frac{1000 \cdot[\text { Pmodule }+ \text { Pinv }+ \text { Pest }] \cdot P p+439,9 \cdot N \mathrm{mod} \cdot(\mathrm{fc} \cdot \mathrm{Nmod})^{-0,259}+A T}{(1-\mathrm{MB})}$

Where,

Pmodule: cost of the module, in $€ / \mathrm{Wp}$. As a guide, these values are proposed in Table 6, which shows those that have been considered for the elaboration of this project:

Table 6. Proposed Module cost in $€$ / Wp (year 2019)

\begin{tabular}{|l|c|c|}
\hline \multicolumn{1}{|c|}{ Module } & $330 \mathrm{Wp} /$ Policristalline & $375 \mathrm{Wp} /$ Monocristalline \\
\hline $75 \mathrm{kWh}-250 \mathrm{kWp}$ & 0.25 & 0.29 \\
\hline $250 \mathrm{kWp}-750 \mathrm{kWp}$ & 0.24 & 0.28 \\
\hline $750 \mathrm{kWp}-2500 \mathrm{kWp}$ & 0.23 & 0.27 \\
\hline
\end{tabular}

Pinv: the cost of investors, in $€ / \mathrm{Wp}$. If the power of inverters is unknown, the following relationship can be considered valid:

Power inv $(\mathrm{Wn})=0,8 \cdot \operatorname{Pmod}(\mathrm{Wp})$

The following values in Table 7 are proposed in case there is no guide value:

Table 7. Proposed cost of inverter in $€ / W p$ (year 2019)

\begin{tabular}{|c|c|}
\hline Power & Cost $(€ / \mathrm{Wp})$ \\
\hline $75 \mathrm{kWh}-250 \mathrm{kWp}$ & 0.070 \\
\hline $250 \mathrm{kWp}-750 \mathrm{kWp}$ & 0.055 \\
\hline $750 \mathrm{kWp}-2500 \mathrm{kWp}$ & 0.045 \\
\hline
\end{tabular}

Pest: cost of the structures, in $€ / W p$. In order to work with normalized values, the total cost of the structures must be divided by the power of installed modules. As a guide, the values in Table 8 are proposed, which are those that have been considered for the elaboration of this project, with the costs of the option with aluminum strips: 
Table 8. Proposed cost of structures in $€ / \mathrm{Wp}$ (year 2019)

\begin{tabular}{|c|c|c|c|c|}
\hline \multicolumn{1}{|c|}{ Power } & $\begin{array}{c}\text { Counterweight, 330 } \\
\text { Wp module }\end{array}$ & $\begin{array}{c}\text { Counterweight, 375 } \\
\text { Wp module }\end{array}$ & $\begin{array}{c}\text { Battens, 330 Wp } \\
\text { module }\end{array}$ & $\begin{array}{c}\text { Battens, 375 Wp } \\
\text { module }\end{array}$ \\
\hline $75 \mathrm{kWp}-750 \mathrm{kWp}$ & 0.060 & 0.053 & 0.121 & 0.106 \\
\hline $750 \mathrm{kWp}-2500 \mathrm{kWp}$ & 0.057 & 0.05 & 0.115 & 0.101 \\
\hline
\end{tabular}

The counterweight solution being the support system patented by Solarbloc, which is only recommended for roof installations that support a high additional weight. The batten solution is a metallic aluminum structure that is anchored to the roof straps. In any case, it will always be more accurate to have a formal quote from a frame manufacturer.

Pp: the total peak power of the installation, calculated in step 1.

fc: correction factor, value:

Modules of 60 cells: $\mathrm{fc}=5 / 6$

Modules of 72 cells: $\mathrm{fc}_{\mathrm{C}}=1$

This correction factor allows that in the final cost of the plant, it is considered that the 60-cell modules present less power. Therefore, the cost of wiring, grounds, and protections that they entail is proportionally lower than the 72-cell modules.

Nmodule: number of modules in the plant.

AT: cost of the voltage elevation system if necessary. Its value is zero for any installation connected in Low voltage. The following value is proposed for estimating calculations, but it is more advisable to have a formal offer from an installation company of transforming systems:

If it is a low voltage connection $\rightarrow \mathrm{AT}=0$

If it is a high voltage connection $\rightarrow \mathrm{AT}=56450 €$

MB: gross margin of the facility, office costs and industrial profit. $12 \%(6 \%+6 \%)$ is proposed as a reference value

The OPEX is obtained directly from expression (1):

annual OPEX $=0,01 \cdot$ CAPEX

This value being the maintenance price for year 1 .

Step 4: Calculate the plant's LCOE

If desired, Equation (2) can be used with the help of a spreadsheet. However, the simplification used in the expression can be considered valid

$\operatorname{LCOE}\left(\frac{€}{M W h}\right)=\frac{(1+L) \cdot \frac{r(1+r)^{n}}{(1+r)^{n}-1} \cdot \operatorname{CAPEX}(€)+\operatorname{OPEX}\left(\frac{€}{\text { año }}\right)}{\text { Production }_{\text {year } 1}(M W h)}$

Production in year 1 is calculated in step 2, while CAPEX and OPEX have been calculated in step 3 . The rest of the parameters are:

L: cost of the building license compared to the cost of the EPC (\%). If it is not known, it can be considered $4 \%$ for installations in Spain, although it can be consulted directly at the City Hall of the building in which the installation is carried out.

r: discount rate (\%). For EPC type photovoltaic installations, it is recommended to use $6 \%[9,19]$.

n: useful life of the plant: It is recommended to use a value of 30 years [19].

\subsection{Accuracy of the developed models}

The models described in the previous section have been compared with the results of the simulations carried out: 


\section{Installed peak power}

In Figure 17, the actual results are compared with those obtained through Expression (7) with the results of the model:

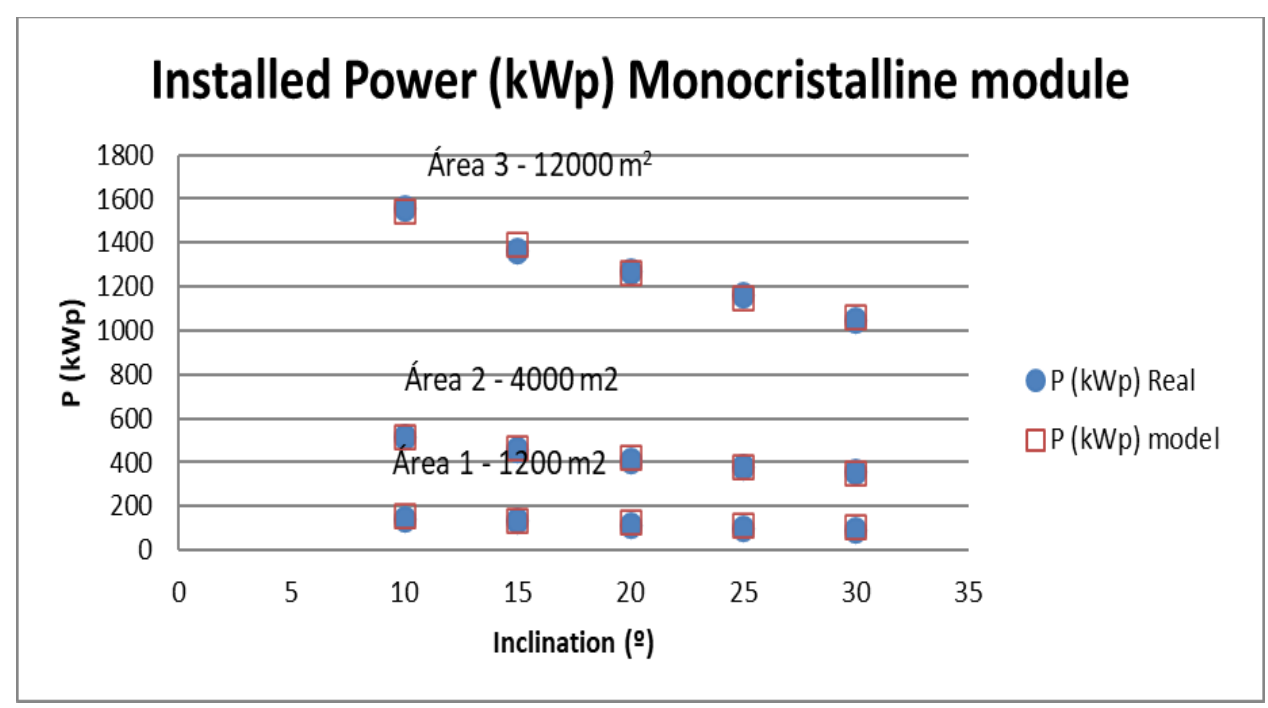

Figure 17. Real installed power and power estimated by the model

As can be seen, the actual results practically overlap with the values obtained with the model. This deviation increases in area 1, since the calculated values are less conservative than the real ones due to the need in the real case to eliminate modules to adjust the number of modules per string. The mean relative error is $4.2 \%$.

Yield

The Yield that the model predicts has been calculated for the 120 cases studied. The mean relative error of the 120 cases is $0.44 \%$, although it is true that the precision has been verified for the same location, so this result does not allow us to verify the precision it has in other locations within the same range. However, it is important to bear in mind that the result depends on the Global Horizontal Irradiation that is introduced into the equation and that it is the main climatological variable.

\section{Plant CAPEX}

To verify the accuracy of the plant's calculation methodology, the cost of each of the facilities has been recalculated based on the desired power. In this case, the precision of the variable part is compared on the one hand (that is, without considering the costs of modules, inverters, and structures) and on the other hand the final result, to see the precision of the part whose cost is obtained from the regression and see how it affects entering the proposed values for the main equipment. Table 9 presents these results:

Table 9. Model error for the three base cases in the calculation of normalized costs

\begin{tabular}{|l|c|c|}
\hline \multicolumn{1}{|c|}{ Case } & Model error - Other costs & Model error - CAPEX \\
\hline $10^{\circ}$-Mono-1200 & $5.01 \%$ & $3.92 \%$ \\
\hline $10^{\circ}$-Mono-4000 & $6.51 \%$ & $5.61 \%$ \\
\hline $10^{\circ}-$-Mono-12000 & $2.22 \%$ & $2.61 \%$ \\
\hline
\end{tabular}

The mean relative error of the 30 cases for the calculation of CAPEX (discounting modules, invertors and structures) is $3.47 \%$. In the case of including all costs, this error drops to $2.57 \%$. For its calculation, the costs proposed by the model have been considered, not the actual costs used, which vary in the case of investors.

\section{LCOE Calculation}


As previously described, the LCOE modeling has been carried out using an analytical approach proposed by the NREL, neglecting the effect of module degradation. In Figure 18 it can be seen that the differences between the real LCOE and the one predicted by the analytical model proposed in Equation (17) are quite small:

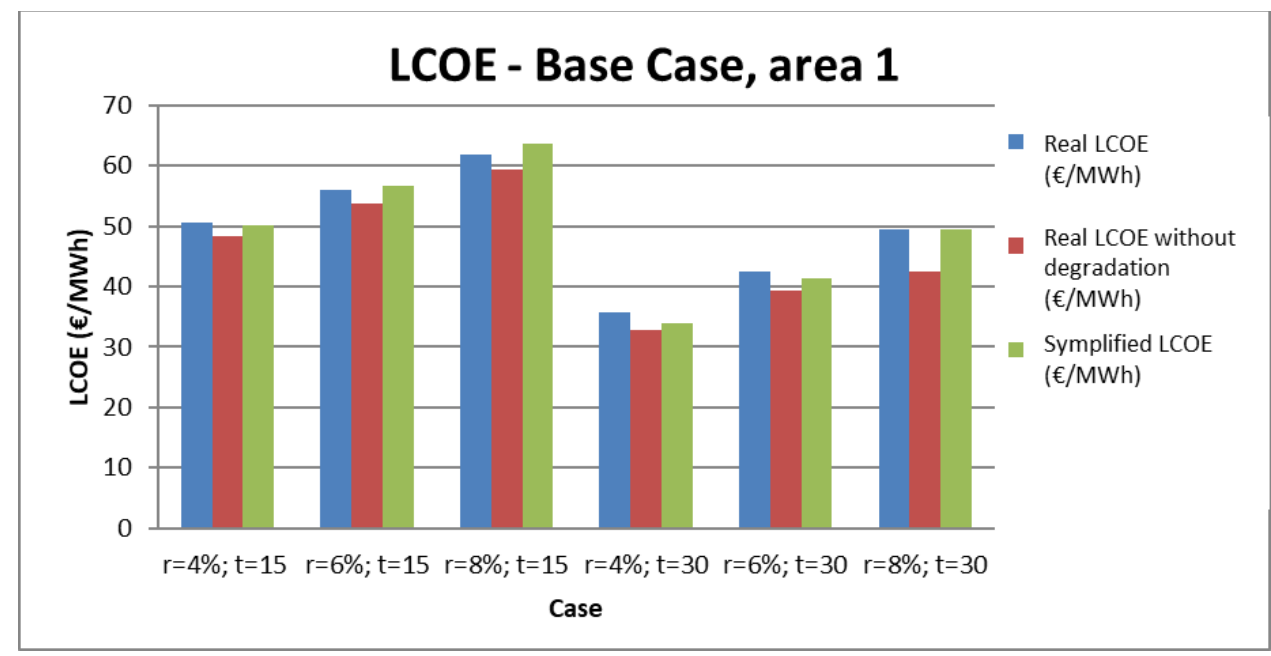

Figure 18. Deviation of the model LCOE with respect to the calculated LCOE

These differences have been calculated for the base case of area 1, and are equivalent to those obtained for other facilities, since the precision of the approximation used causes the error. Table 10 shows the relative error of the LCOE calculation.

Table 10. Relative error of the LCOE calculation approximation as a function of the parameters involved

\begin{tabular}{|c|c|c|}
\hline$r(\%)$ & Years & Relative error (\%) \\
\hline 4 & 15 & $0.95 \%$ \\
\hline 6 & 15 & $1.09 \%$ \\
\hline 8 & 15 & $3.16 \%$ \\
\hline 4 & 30 & $5.01 \%$ \\
\hline 6 & 30 & $2.33 \%$ \\
\hline 8 & 30 & $0.26 \%$ \\
\hline
\end{tabular}

That is, the mean relative error of this approximation is $2.13 \%$.

\section{Conclusions}

The conclusions obtained after carrying out the calculations of the cases studied, and the modeling are:

The maximum installable power increases linearly with the area used. In the area of $1200 \mathrm{~m} 2$, its value ranges between $81.5 \mathrm{kWp}$ and $142.5 \mathrm{kWp}$, while for installations of $12000 \mathrm{~m} 2$ this range of values is multiplied by 10 . The oscillations within the same area are due to the inclination (the greater the inclination, the greater the separation between rows, and therefore the lower the installable power) and the peak power of the installed modules, the installable power being almost $14 \%$ higher in the case of installations with PERC monocrystalline modules.

The Yield depends fundamentally on the location, mainly due to the variation in Global Horizontal Radiation (which in the cases studied goes from $1255 \mathrm{kWh} / \mathrm{m}^{2}$. Bilbao year to $1935 \mathrm{kWh} / \mathrm{m}^{2}$. Lanzarote year), and by temperature, which decreases production 
by lowering the performance of the modules. The Yield also increases with the incline, obtaining the maximum in the $30^{\circ}$. The $\mathrm{PR}$ of the installation is higher in the monocrystalline modules used, since the improvement implied by having PERC cells increases their performance in the first hours of the day and at high temperatures, and this improvement was not included in the polycrystalline modules considered.

The CAPEX of the plant increases with the available surface, but to make a correct analysis, it is more appropriate to normalize its value to $€ / \mathrm{Wp}$. In comparing normalized values, the CAPEX of the cases studied ranges between $€ 0.72$ and $0.83 / \mathrm{Wp}$ for $1200 \mathrm{~m}^{2}$ facilities and between $€ 0.59$ and 0.64 / Wp for facilities of $12000 \mathrm{~m}^{2}$. There is a decrease in this ratio with power due to the economy of scale, which is especially significant for small plants. The variation with the type of module is not very significant, while the inclination does affect the ratio since it modifies the installable power.

If elements break down the CAPEX, the module represents approximately $40 \%$ of the cost, while the inverter represents an average of $8 \%$, the structure $10 \%$, and the assembly $12 \%$. The rest of the elements, which include wiring and protections and the costs of the business structure, engineering, and industrial profit, account for an average of $29 \%$ of the total. This dependence on the cost of the modules and inverter is much lower than in previous times, which had module prices more than ten times higher than today. The decrease in the dependence on the cost of the modules partly explains why the inclinations currently used are lower or why two-axis tracking systems are not used.

OPEX has been estimated at an annual cost of 1\% of CAPEX, representing its minor importance in estimating the LCOE of facilities, especially in industrial self-consumption plants, which have high discount rates.

For the calculation of the LCOE of the plant, it affects both the normalized CAPEX of the facility and the Yield. For this project, fixed discount rates of $6 \%$ and a useful life of 30 years have been considered, and LCOE values of between $€ 29$ and $€ 39$ / MWh are obtained for the best location (Seville), and values between 45 and $59 €$ / MWh for the worst location studied (Bilbao). This range within the same location is mainly due to the size of the plant due to economies of scale. It also affects the variation of the inclination used (The optimum is $10^{\circ}$ in Lanzarote and $20^{\circ}$ in the rest of the locations since, on the one hand, the inclination improves the Yield but makes the installed Wp more expensive). Comparison of the two types of modules used does not show significant differences in terms of LCOE.

The other parameters considered, which are the discount rate and the useful life of the plant, also have great importance in calculating the LCOE. The same installation with a discount rate of $4 \%$ presents an LCOE of $€ 36 /$ MWh. For a discount rate of $8 \%$ would have an LCOE of $€ 49$ / MWh. On the other hand, an installation with a 15-year useful life that presents an LCOE of $€ 56$ / MWh, if studied at 30 years, its energy cost would decrease to $€ 42$ / MWh. That is why correctly assessing the risk of self-consumption facilities to apply the appropriate discount rate and period of life is one of the most important parts to evaluate this type of asset as a financial product.

A series of numerical models have been generated that allow to quickly estimate the maximum installable power for a flat roof intended for self-consumption and its production, its cost, and its LCOE. For its calculation, it is necessary to carry out a series of steps in which proposed costs of modules, structures and inverters can be applied, but these values can be modified in case of having known prices (which allows the models to remain valid even if module cost fluctuates or module performance improves).

To estimate the maximum installable power, it is only necessary to know the area, the performance of the module, and the desired inclination. For the Yield, the variables come down to location, the GHI of that location, and the slant of the modules. The production is obtained as the product of the two previous results.

The calculation of CAPEX requires the use of six calculation variables, for which current values are proposed if they are unknown. The analysis of the LCOE can be simplified to a single analytical calculation, which in turn implies a loss of precision 
concerning the usual calculation methodology. As in CAPEX, most of the variables are left for the reader to enter, proposing values if they are not known.

The relative error of the numerical models for estimating the installable power with respect to the cases evaluated in the project itself is $4.2 \%$ on average, while the relative error of the Yield is less than 1\%. Naturally, the very low error of the Yield is partly because the precision has been evaluated with the cases that have served to generate the model, but no significant deviations can be expected as long as there are modules and investors of similar technology. and the appropriate wiring sections are respected in the design phases. The mean relative error of the normalized CAPEX is $3.5 \%$ on average concerning the cases studied, while the simplification in the calculation of the LCOE leads to an error of $2.1 \%$.

The developed models allow to quickly calculate the LCOE with various slopes and module technologies to check which installation approach will have a lower LCOE (and consequently a shorter payback period). In addition, it allows the reader to have a quick idea of the installable power, the cost of the installation, its production, and its LCOE, without having to carry out the basic engineering of the different installations or simulate each case separately. However, it is recommended to use these models as support and never as a rigid and absolute calculation methodology since it simplifies the multiple variables that can appear in a photovoltaic installation.

\section{Future research}

This project tries to generate models that facilitate the estimation of the main parameters of a photovoltaic installation. However, the scope of this work is limited to sloped roof installations, intended for industrial self-consumption, and which have antidrift systems.

The methodology developed can be partly applied to rooftop coplanar installations if the costs of the structures are known. However, for the study of production, the azimuth of the installation in coplanar roofs is a fundamental parameter to consider. One of the aspects that could be studied in the future would therefore be the application of the models to coplanar installations, including the azimuth variable to the modeling of the Yield of the installations.

Another future line that would improve the models developed would be the generation of a final calculation step to obtain both the installation payback and annual savings. For this, it would be necessary to leave as an input variable the owner's electricity rates and the expected degree of self-consumption of the installation. It could also be possible to compare the proposal with anti-spilling systems with that with compensation systems. The cost of connection and access fees would conflict with the income from the export of unused energy.

Finally, it would be of great interest a previous step of the model that allows knowing the recommended power to install according to the owner's consumption (which should be a known variable). The model developed covers the entire available area, but this step would help to size the installation, the available area, and the owner's consumption according to two criteria.

\footnotetext{
Author Contributions: For research articles with several authors, a short paragraph specifying their individual contributions must be provided. The following statements should be used “Conceptualization, A.R.-M. and C.R.-M.; methodology, A.R.-M. and C.R.-M.; software, A.R.-M.; validation, A.R.-M., and C.R.-M.; formal analysis, A.R.-M.; investigation, A.R.-M. and C.R.-M.; resources, A.R.-M.; data curation, A.R.-M.; writing-original draft preparation, A.R.-M. and C.R.M.; writing - review and editing, A.R.-M. and C.R.-M.; visualization, A.R.-M.; supervision, C.R.-M.; project administration, C.R.-M.. All authors have read and agreed to the published version of the manuscript.
}

Funding: This research received no external funding. 
Data Availability Statement: All data used in the study are publicly available. The repositories are refenced in the text.

Conflicts of Interest: The authors declare no conflict of interest.

\section{References}

[1] Kavlak, G., 2018. Evaluating the causes of the cost reduction in photovoltaic modules. Energy Policy. Massachusetts, USA. [2] International Renewable Energy Agency (IRENA). Renewable Power Generation Costs In 2020. [Accessed on June 13, 2021]. Available online at: https://www.irena.org/Lmedia/Files/IRENA/Agency/Publication/2020/Jun/IRENA Power Generation Costs 2019.pdf

[3] Unión Nacional Española de Fotovoltaica (UNEF). Informe Anual de 2018. 2017: El Inicio de una Nueva Era en el Sector Fotovoltaico. [Accessed on July 18, 2019]. Available online at: https://unef.es/wpcontent/uploads/dlm uploads/2018/09/memo unef 2017.pdf

[4] Pikerel, K. Latest Lazard LCOE Analysis Finds Utility-Scale Solar Now at or below Cost of Conventional Generation. [Accessed on July 18, 2019]. Available online at: https://www.solarpowerworldonline.com/2018/11/latest-lazard-lcoeanalysis-finds-utility-scale-solar-now-at-or-below-cost-of-conventional-generation/

[5] Willuhn, M. 2019. La subasta portuguesa bate record mundial con 14,8 €/MWh. PV Magazine. [Accessed on August 3, 2019]. Available online at: https://www.pv-magazine.es/2019/07/31/la-subasta-portuguesa-bate-el-record-mundial-con$\underline{148-\mathrm{e}-\mathrm{mwh} /}$

[6] International Energy Agency (IEA). Statistic Data Browsers. Accessed on June 13, 2021]. Available online at: https://www.iea.org/statistics/

[7] Renewable Energy Policy Network for the 21st Century (REN21). Renewables2016, Global Status Report. [Accessed on July 18, 2019]. Available online ht: https:/www.ren21.net/wpcontent/uploads/2019/05/REN21 GSR2016 FullReport en 11.pdf

[8] International Energy Agency - Photovoltaic Power Systems Programme (IEA-PPSP). A Snapshot Of Global Photovoltaics. [Accessed on July 18, 2019]. Available online at: http://www.iea-pvps.org/index.php?id=266

[9] Irena. Statistics, Capacity and Generation. [Accessed on June 13, 2021]. Available online at: https://irena.org/Statistics/View-Data-by-Topic/Capacity-and-Generation/Country-Rankings

[10] National Renewable Energy Laboratory (NREL). 2016. Best Practices in Photovoltaic Systems Operation and Maintenance. Segunda Edición. [Accessed on July 12, 2019] Available online at https://www.nrel.gov/docs/fy17osti/67553.pdf

[11] Electric Power Research Institute (EPRI). 2015. Budgeting for Solar Plants O\&M: Practices and Pricing. [Accessed on 23 July, 2019]. Available online at: https://prod-ng.sandia.gov/techlib-noauth/access-control.cgi/2016/160649r.pdf

[12] Solar Bankability. Best Practice Guidelines for PV Cost Calculation, Accounting for Technical Risks and Assumptions in PV LCOE. [Accessed on 30 June, 2019]. Available online at https://www.tuv.com/content-media-files/mastercontent/services/products/p06-solar/solar-downloadpage/solar-bankability d3.2 best-practice-guidelines-for-pv-costcalculation.pdf

[13] Muhleisen, W. 2019. Scientific and economic comparison of outdoor characterization methods for photovoltaic power plants. Renewable Energy. Elsevier, 134, 321-329.

[14] Mermoud, A. 2014. PVSYST User's Manual. Switzerland

[15] National Renewable Energy Laboratory (NREL). Simple Levelised Cost of Energy Calculator Documentation. [Accessed on July 30, 2019]. Available online at https://www.nrel.gov/analysis/tech-lcoe-documentation.html

[16] Short, J., A Manual for the Economic Evaluation of Energy Efficiency and Renewable Energy Technologies. NREL. 1995. 
[17] Meteoblue Climate (modelled). [Accessed on August 6, 2019]. Available online at https://www.meteoblue.com/es/tiempo/historyclimate/climatemodelled/sevilla espa\%c3\%b1a 2510911

[18] ADRASE (Acceso a Datos de Radiación Solar en España). Mapa Interactivo de la Península. [Accessed on 28 July, 2019]. Available online at: http://www.adrase.com/

[19] National Renewable Energy Laboratory (NREL). 2017. U.S. Solar Photovoltaic Systems Cost Benchmark: Q1 2017. 